\title{
Acute Coronary Syndromes in Semi-Urban African Areas: Clinical Aspects and Management in Ziguinchor (Senegal)
}

\author{
Simon Joël Manga ${ }^{1 *}$, Mame Diarra Mbaye ${ }^{1}$, Sidy Lamine Sy², Quinta Te Indafa1 \\ ${ }^{1}$ Cardiology Departement, Hospital de la Paix, Assane Seck University of Ziguinchor, Ziguinchor, Senegal \\ ${ }^{2}$ Cardiologie Departement, Fann National University Center, Dakar Cheikh Anta Diop University, Ziguinchor, Senegal \\ Email: *mangasimon@yahoo.fr
}

How to cite this paper: Manga, S.J., Mbaye, M.D., Sy, S.L. and Te Indafa, Q. (2021) Acute Coronary Syndromes in Semi-Urban African Areas: Clinical Aspects and Management in Ziguinchor (Senegal). Open Journal of Emergency Medicine, 9, 179-187.

https://doi.org/10.4236/ojem.2021.94018

Received: October 4, 2021

Accepted: November 12, 2021

Published: November 15, 2021

Copyright $\odot 2021$ by author(s) and Scientific Research Publishing Inc. This work is licensed under the Creative Commons Attribution International License (CC BY 4.0).

http://creativecommons.org/licenses/by/4.0/

\section{(c) (i) Open Access}

\begin{abstract}
Context and Objectives: Acute coronary syndromes (ACS) constitute a major medical emergency. In Senegal, outside the capital Dakar, there is a lack of appropriate care structures. The objective of this work was to study the ACS treatment in the city of Ziguinchor. Methodology: This was a retrospective study of acute coronary syndromes' cases admitted to the two-level two hospitals in the city of Ziguinchor from January 1, 2016 to December 31, 2019. We included all patients with acute angina pain at rest and/or electrocardiographic changes in at least two contiguous leads. The data were analysed using sphinx V5 software. Results: 57 cases were collected. The average age was $60.1 \pm 14.1$ years. There was a male predominance with a sex ratio of 3.7. The majority of patients arrived at the hospital by unsafe delivery (70.5\%). Symptomatology was dominated by typical angina pain (50.8\%). On the electrocardiogram, a majority of acute coronary syndromes with ST segment shift were observed (70.2\%). Doppler echocardiography found abnormalities in segmental kinetics in $69.8 \%$ of cases. The troponin dosage was performed in 7 patients, i.e. $12.3 \%$. The average time of treatment was $3.4 \pm 4.5$ days. Medical treatment remained standard and no patient was thrombosed. The average hospitalization period was $5 \pm 3.2$ days. The hospital lethality was $7.2 \%$. Conclusion: Acute coronary syndromes constitute a medical emergency. Diagnostic and therapeutic means are lacking in a city like Ziguinchor, hence the importance of good prevention.
\end{abstract}

\section{Keywords}

Acute Coronary Syndromes, Clinic, Management, Ziguinchor 


\section{Introduction}

Cardiovascular disease remains today the main cause of death in Western countries and the second cause of death in France behind cancer. According to the World Health Organization (WHO), 17.5 million deaths were attributable to cardiovascular disease worldwide in 2015 , or $31 \%$ of all deaths, including 7.4 million from coronary heart disease alone (13\% of the global total mortality) [1]. Acute coronary syndrome (ACS) consists of the clinical, electrocardiographic and laboratory manifestations associated with coronary atherosclerosis. ACS is a real public health problem. In Europe and the United States, the prevalence of coronary artery disease is changing and the rates vary, depending on the country, from 43 to $144 / 100,000$ inhabitants per year. Worldwide, the frequency of ischemic heart disease (IHD) is increasing and is the most common cause of death [2].

Acute Coronary Syndromes (ACS) have long been considered less common in sub-Saharan Africa. However, for several years, we have observed their constant increase due to the change in lifestyle, which tends to become westernized but also to diagnostic means, which are becoming more and more efficient, particularly in the urban area [3]. In sub-Saharan Africa, the consequences of this condition are serious because of insufficient prevention, pre-hospital care that remains exceptional, the long delay before hospitalization and the scarcity of adapted reception centers [4]. The World Health Organization estimated that in 2005 ischemic heart disease caused an estimated 361,000 deaths in the African region, and current projections suggest that number will almost double by 2030 [5].

Senegal is no exception, since more than half of patients admitted for ACS arrive after the twelfth hour [6] [7] [8] and pre-hospital care is almost non-existent outside the capital, Dakar. The city of Ziguinchor, which is located in the south of the country, has never been the subject of a study on ACS. We have therefore set ourselves the objectives of studying the epidemiological and clinical aspects and the acute coronary syndromes' treatment.

\section{Patients and Methods}

This is a retrospective study carried out at the Emergency Reception Service of the Ziguinchor Peace Hospital and at the Cardiology Service of the Ziguinchor Regional Hospital Center concerning patients admitted for an acute coronary syndrome from January 1, 2016 to December 31, 2019.

We included in our study all patients of both sexes, presenting acute angina pain at rest and/or electrocardiographic changes in at least 2 contiguous leads of elevation or under shift type significant of the ST segment or the negative or positive $\mathrm{T}$ waves, sharp and symmetrical. We excluded patients with stable angina, chest pain and/or non-specific electrocardiographic changes, semi-recent or sequelae myocardial infarction and non-exploitable records.

The studied parameters were prevalence, age, sex, geographic origin, cardi- 
ovascular risk factors, clinical and paraclinical aspects (Electrocardiogram, biology, and Doppler echocardiography), time to treatment, therapeutic modalities, intra-hospital course and prognosis.

We analyzed the statistical data using Sphinx V5 software. Chi-square test was used and was considered significant for a p value $<0.05$.

We made sure that the confidentiality of participants' study was ensured by using personal identification numbers on data collection forms instead of names. Personal identifiers will not be included in study reports. All study records are confidential.

\section{Results}

During the period of our study, 1342 patients had been admitted to our study sites for a cardiovascular disease, including 75 for an acute coronary syndrome corresponding to a hospital prevalence of $5.6 \%$. Only the 57 patients' records had been retained, of which 40 admitted for an ACS with persistent ST segment elevation and 17 admitted for an ACS without ST segment elevation.

The male sex predominated with 45 men (78.9\%) and 12 women (21.1\%), for a sex ratio of 3.7.

The average age of the patients was $60.1 \pm 14.1$ years with extremes of 31 and 90 years. The peak was in the 61 to 70 age group (28.1\%). An ACS of the young subject was noted in 4 patients (7\%) with an age of less than 40 years. For men, the average age was 59.8 years and 61.1 years for women.

The majority of patients (65.4\%) were from the city of Ziguinchor, 30.9\% from surrounding villages and 3.6\% from Guinea Bissau.

The cardiovascular risk factors are summarized in Table 1.

The diabetics were all type II. Smoking was active for all patients who were exclusively male. The number of pack-years averaged 30.6 with extremes of 2 and 80.

The average cardiovascular risk factor index was 1.9. The majority of patients (59.6\%) were multifactorial. Only one patient had no risk factors found.

Table 1. Cardiovascular risk factors.

\begin{tabular}{ccc}
\hline CVRF & Number of patients & Percentage (\%) \\
\hline HBP & 29 & 50.9 \\
Hypercholesterolemia & 18 & 31.6 \\
Obesity & 14 & 24.6 \\
Sedentary lifestyle & 14 & 24.6 \\
Diabetes & 13 & 22.8 \\
Smoking & 9 & 15.8 \\
Menopause & 6 & 50 \\
\hline
\end{tabular}

CVRF: Cardiovascular risk factors; HBP: High Blood Pressure. 
Typical angina pain (50.9\%), dyspnea (43.9\%), digestive signs (26.3\%) and atypical chest pain $(22.8 \%)$ dominated the reasons for consultations.

The abnormalities noted on the examination were left heart failure $(21.1 \%)$, global heart failure (8.8\%), cardiogenic shock (1.8\%) and a heart sound deafness (21.1\%).

The analysis of the electrocardiographic tracings made it possible to retain the diagnoses of ACS with persistent ST segment elevation in 40 patients $(70.2 \%)$ and of ACS without ST segment elevation in 17 patients (29.8\%). The anterior territory was the most represented (68.4\%) followed by the lower territory (19.3\%). An extension to the right ventricle was found in 4 patients (7\%). The location of electrocardiographic abnormalities is summarized in Table 2.

Troponinemia was positive in all 7 patients in whom it was measured with an averge level of $3.5 \pm 3.1 \mathrm{ng} / \mathrm{l}$.

The admission blood glucose taken in 26 patients (45.6\%) was upper to 1.24 $\mathrm{g} / \mathrm{l}$ in 6 patients $(23.1 \%)$ including 5 diabetics. It was on average $1.8 \pm 1.2 \mathrm{~g} / \mathrm{l}$.

Cholesterol and triglyceride levels were measured in 33 patients (57.9\%). Among them, 11 patients (33.3\%) had total cholesterol levels above 2 g/l; 5 patients (15.2\%) had HDL-cholesterol levels below $0.4 \mathrm{~g} / \mathrm{l}, 13$ patients (39.4\%) had an LDL-cholesterol level upper to $1.3 \mathrm{~g} / \mathrm{l}$ and 3 patients $(9.1 \%)$ had a triglyceridemia superior to $1.5 \mathrm{~g} / \mathrm{l}$.

Biological renal failure was found in $17 / 49$ patients $(34.7 \%)$ and positive $\mathrm{C}$ Reactive protein (CRP) in $14 / 24$ patients (58.3\%).

The results of the biology are summarized in Table 3.

Table 2. Location of electrocardiographic abnormalities.

\begin{tabular}{ccccc}
\hline Territory & ST+ & ST- & Total & Percentage (\%) \\
\hline Prior & 3 & 3 & 6 & 10.5 \\
Antero-septal & 10 & 1 & 11 & 19.3 \\
antero-septo-apical & 10 & 0 & 10 & 17.5 \\
Extended anterior & 9 & 3 & 12 & 21.1 \\
Apico-lateral & 1 & 3 & 4 & 7 \\
Septo-apico-lateral & 0 & 1 & 1 & 1.7 \\
Deep septal & 1 & 0 & 1 & 1.7 \\
Inferior & 6 & 3 & 9 & 15.8 \\
Infero-lateral & 1 & 1 & 2 & 3.5 \\
Lateral & 1 & 4 & 5 & 8.8 \\
Circumferential & 1 & 1 & 2 & 3.5 \\
extension to the RV & 4 & 0 & 4 & 7 \\
\hline
\end{tabular}

$\mathrm{RV}$ : right ventricle. 
Table 3. Summary of biological parameters.

\begin{tabular}{cccc}
\hline \multicolumn{2}{c}{ Biological parameters } & Average values & Extreme \\
\hline Troponinn (ng/ml) & $3.5 \pm 3.1$ & $0.16-6.5$ \\
\hline Glycemia (g/l) & & $1.8 \pm 1.2$ & $0.76-6.5$ \\
\hline & Total & $1.9 \pm 0.5$ & $1.15-3.05$ \\
Cholesterol (g/l) & HDL & $0.5 \pm 0.2$ & $0.27-1.05$ \\
& LDL & $1.2 \pm 0.5$ & $0.12-2.11$ \\
\hline Triglycerides & & $0.9 \pm 0.4$ & $0.44-2.09$ \\
\hline CRP (mg/l) & $24.7 \pm 29.5$ & $0-96$ \\
\hline
\end{tabular}

The Doppler echocardiography performed in 43 patients (75.4\%) found segmental kinetics abnormalities in $69.8 \%$ of patients with a predominance of hypokinesia (58.1\%) and most often affected the septal wall (60.5\%), an impaired left ventricular systolic function in $51.2 \%$ of patients with an average left ventricular systolic ejection fraction of $52.4 \% \pm 16.1 \%$ (extreme $18 \%$ and $77 \%$ ). It also found a left ventricular dilation in $34.9 \%$ of patients and moderate abundant pericardial effusion in one patient. The average time to treatment was $3.4 \pm 4.5$ days. 13 patients were seen before 12 hours after the onset of symptoms.

Therapeutically, no patient had undergone thrombolysis. The used drugs are summarized in Table 4.

After an average hospitalization of 5 days \pm 3.2 , the development in a hospital environment was favorable in $43.6 \%$ of cases. Complications occurred in $56.4 \%$ of the patients.

The hospital lethality of ACS was 7.2\%.

Multivariate analysis was performed for prognostic factors.

We investigated the influence of various factors on the prognosis using the presence of a complication and death as the combined criteria.

The Fisher test used was considered significant for a p value $<0.05$.

On the list of variables tested, two are linked to the development variable (favorable vs. death/complication) in bivariate mode. Indeed, the Fisher tests above between the explanatory variables and the dependent development variable show that at the 5\% level, we cannot reject the null hypothesis of independence for any variable except the number of risk factors superior to $2(\mathrm{p}=0.026)$ and the treatment length upper to 12 hours $(p=0.000)$. Then, multivariate analysis was performed to test all variables simultaneously. A logistics model with a Stepwise approach carried out using the Stata software gave the following results.

At the significance level of $5 \%$, the variables glycemia on admission superior to $1.24 \mathrm{~g} / \mathrm{L}$, treatment length upper to 12 hours and left ventricular ejection fraction less than $50 \%$ are linked to the evolution of the assumption of responsibility. An admission glycemia superior to $1.24 \mathrm{~g} / \mathrm{L}(\mathrm{OR}=6.19[1.21-31.72])$, a recovery period of more than 12 hours $(\mathrm{OR}=4.99$ [1.25 - 19.92]) and a left ventricular ejection fraction of less than $50 \%(\mathrm{OR}=5.94[1.30-27.01])$ are associated with a risk of death and/or complications. 
Table 4. Summary of the main used drugs.

\begin{tabular}{ccc}
\hline Used drugs & Number of patients & Percentage (\%) \\
\hline Low molecular weight heparin & 32 & 63.2 \\
Aspirin & 55 & 96.5 \\
Clopidogrel & 42 & 73.7 \\
Beta-blockers & 33 & 57.9 \\
Converting enzyme inhibitors & 48 & 84.2 \\
Statins & 47 & 82.5 \\
Nitro derivatives & 12 & 21.1 \\
Analgesics & 31 & 54.4 \\
Anxiolytics & 4 & 7 \\
Diuretics & 25 & 43.9 \\
Insulin & 6 & 10.5 \\
Oral anti diabetics & 3 & 5.3 \\
Anti ulcer & 22 & 38.6 \\
\hline
\end{tabular}

\section{Discussion}

In Africa, there is a steady increase in the prevalence of ischemic heart disease. Indeed, it went from $4.05 \%$ in 2006 [7] to $13.5 \%$ in 2013 [6]. The constant increase in the prevalence of ACS in Africa could be explained on the one hand by the modification of the populations' lifestyle and on the other hand, by the increase of human and material resources favoring the diagnosis. In our work, the hospital prevalence of ACS was 5.6\%.

The sex ratio in our study is 3.7 in favor of men. This is corroborated by data from the literature [7] [8] [9]. However, this predominance tends to decrease with age, which could be explained by the gradual decline in estrogen during pre-menopause [10].

The average age of our patients was $60.1 \pm 14.1$ years. Khalfallah [11] and Mboup [7] were respectively 55.5 years old in Tunisia and 57.1 years old in Dakar. In the European and North American series, the average age of onset of ACS was higher. He was 67 and 62.6 years old respectively in France [12] and Canada [13]. This disparity could be explained by the much higher life expectancy in developed countries and the early cardiovascular risk factors' treatment in these countries.

The most common cardiovascular risk factors found in our study were high blood pressure, high cholesterol, diabetes, active smoking, obesity and physical inactivity. This observation was noted in the INTERHEART Africa study [14] where these risk factors were implicated in $89.2 \%$ of the first episodes of myocardial infarction in sub-Saharan Africa. The increasing magnitude of these cardiovascular risk factors in our regions explains the increased incidence of coro- 
nary heart disease.

Typical anginal pain dominated the functional symptomatology of our patients as reported in the literature [6] [7] [15]. We found digestive signs in $26.3 \%$ of cases, which underlines the importance of the ECG in this context.

The distribution of clinical ACS forms in our study is superimposable on certain data described in the African literature [15] [16]. The preponderance of the anterior territory involvement (68.4\%) in our study confirms a well-established fact in previous studies [4] [15] [16].

Seck [4] as well as Mboup [7] had measured troponinemia in $96 \%$ and $81.3 \%$ of patients, respectively, in 2006 in Dakar. This reflects a better integration of this biological parameter in the diagnostic process of painful thoracic syndromes at the emergency reception services of Dakar hospitals. In our work, it was measured in $12.3 \%$ of patients. This is linked to the inadequacy of the technical platform in the city of Ziguinchor. Equipping peripheral medical structures with means for early diagnosis of ACS (ECG, troponin assay) would greatly contribute to improving the diagnosis of ACS and their treatment.

In our study, individualized systolic left ventricular dysfunction in $51.2 \%$ of patients was a factor of poor prognosis in multivariate analysis as highlighted by Cambou in the USIK study where it was found in $54 \%$ of patients [12]. The treatment was medical in all our patients and consisted of the administration of a double antiplatelet aggregation, an anti-coagulation with a low molecular weight heparin. ACE inhibitors, beta blockers and statins were administered in $84.2 \%, 57.9 \%$ and $82.5 \%$ of patients, respectively.

No patient had benefited from thrombolysis in our study because the treatment times were long and the thrombolytic was not available in most cases, whereas 13 patients $(22.8 \%)$ had been received before the twelfth hour and could have benefited from thrombolysis. The mortality rate in our study, of $7.2 \%$, is lower than that of Thiam in 2000 (10\%) [8] and Mboup in 2006 (15.25\%) [7]. This could presage a transition to lower mortality in our country.

The following factors in our study were risk factors for complications and/or hospital death: a cardiovascular risk factor number superior to $2(\mathrm{p}=0.026)$, admission blood glucose upper to $1.24 \mathrm{~g} / \mathrm{l}(\mathrm{OR}=6.19$ [1.21 - 31.72]), a left ventricular ejection fraction less than $50 \%(\mathrm{OR}=5.93[1.30-27.01])$, a charge superior to $12 \mathrm{~h}(\mathrm{p}=0.000 ; \mathrm{OR}=4.99[1.24-19.92])$. Age was not a factor of poor prognosis in our study, unlike the results of De Matos Soeiro in which, in patients with acute coronary syndromes, age was an important predictor of mortality and complications [17].

The limits of this study are those inherent in any retrospective study, in particular the lack of numerous clinical and paraclinical data.

\section{Conclusion}

ACS is a major medical emergency due to their complications and the mortality they cause in our regions. However, diagnostic and therapeutic means are lack- 
ing in a city like Ziguinchor, hence the importance of properly identifying and controlling the risk factors for atherosclerosis.

\section{Authors' Contribution}

All the authors contributed to the conduct of this work. All authors have read and approved the latest version of this manuscript.

\section{Conflicts of Interest}

The authors declare no conflict of interest.

\section{References}

[1] Porouchani, S. and Lemesle, G. (2019) Infarctus du myocarde: Diagnostic, prise en charge et complications. EMC-Traité de Médecine Akos, 14, 1-14.

[2] Wiel, E., Assez, N. and Goldstein, P. (2019) Stratégie de prise en charge des syndromes coronariens aigus. EMC-Médecine durgence, 14, 1-13. https://doi.org/10.1016/S1959-5182(12)59019-7

[3] Ondze-Kafata, L.I., Bianza, J.R., Ngolo-Letomo, K., Otiobanda, G.F., Amounya-Zobo, S. and Bakekolo, R.P. (2014) La Cardiopathie Ischémique au Centre Hospitalier et Universitaire de Brazzaville: Etude de 133 cas. Dakar Médical, 59, 150-157.

[4] Seck, M., Diouf, I., Acouetey, L., Wade, K.A., Thiam, M. and Diatta, B. (2007) Profil des patients admis pour infarctus du myocarde au Service d'Accueil des Urgences de l'Hôpital Principal de Dakar. Médecine Tropicale, 67, 569-572.

[5] Kakou-Guikahue, M., N’Guetta, R., Anzouan-Kacou, J.B., Kramoh, E., N’Dori, R., Ba, S.A., et al. (2016) Optimizing the Management of Acute Coronary Syndromes in Sub-Saharan Africa: A Statement from the AFRICARDIO 2015 Consensus Team. Archives of Cardiovascular Disease, 109, 376-383. https://doi.org/10.1016/j.acvd.2015.12.005

[6] N'guetta, R., Yao, H., Ekou, A., N'cho-Mottoh, M.P., Angoran, I. and Tano, M. (2016) Prévalence et caractéristiques des syndromes coronariens aigus dans une population d'Afrique sub-saharienne. Annales de Cardiologie et d Angéiologie, 65, 59-63. https://doi.org/10.1016/j.ancard.2016.01.001

[7] Mboup, M.C., Diao, M., Dia, K. and Fall, P.D. (2014) Les syndromes coronariens aigus à Dakar: Aspects cliniques, thérapeutiques et évolutifs. Pan African Medical Journal, 19, 126. https://doi.org/10.11604/pamj.2014.19.126.3155

[8] Thiam, M., Cloatre, G., Fall, F., Theobald, X. and Perret, J.L. (2000) Cardiopathies ischémiques en Afrique: Expérience de l'Hôpital Principal de Dakar. Médecine d Afrique Noire, 47, 281-284.

[9] Khalfallah, A.B., Sanna, I., Annabi, N., Ousji, M., Aloui, H. and Naffeti, S. (2005) Valeur prédictive des marqueurs de l'inflammation au cours des syndromes coronaires aigus. Archives des Maladies du Coeur et des Vaisseaux, 985, 899-905.

[10] Dey, S., Flather, M.D., Devlin, G., Brieger, D., Gurfinkel, E.P. and Steg, P.G. (2009) Sex-Related Differences in the Presentation, Treatment and Outcomes among Patients with Acute Coronary Syndromes: The Global Registry of Acute Coronary Events. Heart, 95, 20-26. https://doi.org/10.1136/hrt.2007.138537

[11] Cambou, J.P., Genes, N., Vaur, L., Danchin, N., Renault, M. and Etienne, S. (1998) Epidémiologie de l'infarctus du myocarde en France: Survie à 1 an des patients de l'étude USIK. Archives des Maladies du Coeur et des Vaisseaux, 91, 1103-1110. 
[12] Gupta, M., Doobay, A.V., Singh, N., Anand, S.S., Raja, F. and Mawji, F. (2002) Risk Factors, Hospital Management and Outcomes after Acute Myocardial Infarction in South Asians Canadians and Matched Control Subjects. CMAJ, 166, 717-722.

[13] Steyn, K., Sliwa, K., Hawken, S., Commerford, P., Onen, C. and Damasceno, A. (2005) Risk Factors Associated with Myocardial Infarction in Africa: The Interheart Africa Study. Circulation, 112, 3554-3561. https://doi.org/10.1161/CIRCULATIONAHA.105.563452

[14] Sarr, S.A., Babaka, K., Archich, N., Bodian, M., N'diaye, M.B. and Diao, M. (2017) Profil des patients admis en unité de soins intensifs dans un service de cardiologie de Dakar. Revue CAMES SANTE, 5, 83-87.

[15] Kingue, S., Binam, F., Baonga, B.P., Pouth, S.F., Ouankou, M. and Mouna, W.F. (2000) La maladie coronaire au Cameroun: Aspects épidémiologiques et cliniques, à propos de 30 observations. Cardiologie Tropicale, 26, 7-11.

[16] Coulibaly, S., Diall, I.B., Menta, I., Diakite, M., Ba. H.O. and Diallo, N. (2018) Le Syndrome Coronarien Aigu dans le Service de Cardiologie du CHU du Point G: Prévalence, Clinique, Thérapeutique et Évolution. Health Sciences and Disease, 19, 20-23.

[17] de Matos Soeiro, A., Borba, A.P., Bossa, A.S., Zullino, C.N., de Almeida Soeiro, M.C.F., de Carvalho Andreucci Torres Leal, T., et al. (2016) A Risk-Adjusted Retrospective Data Analysis between Younger and Elderly Patients with Acute Coronary Syndromes-Long-Term Prognosis. Open Journal of Emergency Medicine, 4, 53-61. https://doi.org/10.4236/ojem.2016.43008 